\title{
Redescription of the types of species of Anastatus Motschulsky, 1859 (Hymenoptera: Chalcidoidea: Eupelmidae) described by J.K. Sheng and coauthors
}

\author{
Lingfei PENG ${ }^{1, *}, \mathrm{Lu}_{\mathrm{TANG}}{ }^{2}$ \& Gary A.P. GIBSON ${ }^{3}$ \\ ${ }^{1,2}$ State Key Laboratory of Ecological Pest Control for Fujian and Taiwan Crops, \\ Fujian Provincial Key Laboratory of Insect Ecology, Key Laboratory of Integrated Pest Management \\ for Fujian-Taiwan Crops, Ministry of Agriculture, College of Plant Protection, \\ Fujian Agriculture and Forestry University, Fuzhou, 350002, China. \\ ${ }^{3}$ Honorary Research Associate, Agriculture and Agri-Food Canada, Canadian National Collection \\ of Insects, Arachnids and Nematodes, K.W. Neatby Bldg., 960 Carling Avenue, \\ Ottawa, Ontario, K1Y 4X2, Canada. \\ *Corresponding author: lingfeipeng@,fafu.edu.cn \\ ${ }^{2}$ Email: 974246412@qq.com \\ ${ }^{3}$ Email: gary.gibson@agr.gc.ca \\ ${ }^{1}$ urn:1sid:zoobank.org:author:5FB1448D-3BED-4DC7-8CD8-F0D62DE0D7C7 \\ ${ }^{2}$ urn:lsid:zoobank.org:author:6C524BFF-1674-4E9A-8A32-42A864C02FFC \\ ${ }^{3}$ urn:lsid:zoobank.org:author:77CCFFBE-EBD1-4CC7-ADEC-F8BCD6CF9109
}

\begin{abstract}
Six species of Anastatus Motschulsky, 1859 (Hymenoptera: Eupelmidae) were described from China in Chinese by J.K. Sheng and coauthors in 1997 and 1998: A. dexingensis, A. flavipes, A. fulloi, A. huangi, A. meilingensis and A. shichengensis. This represents almost half the species of Anastatus recorded from China, but no keys were given to differentiate the species and the original descriptions included only simple line drawings to illustrate the species. Because recognition of these species is critical prior to clarifying the Anastatus fauna of China and of the eastern Palaearctic and Oriental regions, we have redescribed the six species in detail in English based on original type material, illustrating the species through macrophotography of type material and providing a key to differentiate females of the species.
\end{abstract}

Keywords. China, Eupelminae, taxonomy, type specimens.

Peng, L., Tang, L. \& Gibson, G.A.P. 2017. Redescription of the types of species of Anastatus Motschulsky, 1859 (Hymenoptera: Chalcidoidea: Eupelmidae) described by J.K. Sheng and coauthors. European Journal of Taxonomy 292: 1-24. https://doi.org/10.5852/ejt.2017.292

\section{Introduction}

Anastatus Motschulsky, 1859 (Hymenoptera: Chalcidoidea: Eupelmidae) is an economically important genus whose members are mostly egg parasitoids and who are natural enemies of many pest insects in 
China and elsewhere (Huang et al. 1974; Liao et al. 1987; Leksawasdi \& Kumchu 1991; Peng \& Lin 2012). Noyes (2016) recorded 13 species of Anastatus from China among a world fauna of about 150 valid described species, including $A$. orientalis Yang \& Choi, 2015, which is an endo-parasitoid in eggs of the spotted lanternfly, Lycorma delicatula (White, 1845) (Yang et al. 2015). Six of the Chinese species of Anastatus were described by Sheng \& Wang or Sheng \& Yu: A. dexingensis, A. flavipes, A. fulloi and A. shichengensis by Sheng \& Wang in Sheng et al. (1997); A. huangi and A. meilingensis by Sheng \& Yu (1998). All were described based on reared material from Jiangxi Province (Oriental) except for A. flavipes, which was also recorded from the Shandong and Heilongjiang provinces (Palearctic). Because the type material was reared, males were associated with females for all species except $A$. dexingensis. The species were described in Chinese with English summaries, and although simple line drawings and differential features were provided to distinguish females from those of other described species, they were not keyed. Since their original description, the species have not been examined or included in any other studies (Noyes 2016), but their recognition is critical prior to clarifying the Anastatus fauna of China and of the eastern Palaearctic and Oriental regions.

In 2015, the first author of the present paper contacted Guohong Wang (second author of Sheng et al. 1997) and was informed that specimens of all six species were still conserved at Jiangxi Agricultural University, Nanchang, China. We subsequently had a chance to examine Sheng's collection with the great help of Prof. Hongyi Wei and Dr. Weichun Li. The present study summarizes the type material, then redescribes and, using macrophotography, illustrates the species based on original type material, paving the way for more comprehensive studies of Anastatus of China. Females were keyed using the Palaearctic revision of Anastatus by Kalina (1981), the only comprehensive revision of the genus-albeit western Palaearctic in scope - and characters are given to differentiate the Chinese species from the names keyed by Kalina (1981). The key of Narendran (2009) was not used because species descriptions are insufficient and there are some inconsistencies between the descriptions and the key.

\section{Material and methods}

This study is based on a total of 512 pinned specimens, almost all Anastatus, found in six boxes of the Sheng collection at Jiangxi Agricultural University, Nanchang, China. Although some specimens had escaped serious damage, 149 (29.1\%) were completely destroyed and more than half of the remainder were poorly preserved, presenting damage to various extents by mildew or partly eaten by insects. The state of preservation of many of the specimens complicates accurate redescription of some characters, particularly exact wing setal patterns. Further complicating the study of Sheng's collection was that many specimens lacked labels, including type labels indicating the designated holotype, allotype or paratypes, and there was not a consistent one-to-one match between each description record and each specimen, which made it difficult to check against the original literature.

The first step in studying Sheng's collection was an attempt to find any specimen with the same label data as recorded in the original descriptions. Sheng sometimes only labeled the first specimen in a column, the rest not bearing any labels. Because all the specimens lacked type labels, we considered the female labeled with "sp. nov." as the holotype of the respective species of that name. All specimens were examined with a stereoscope, and those females that possessed the same characteristics as the female considered to be the holotype, and that were consistent with Sheng's original descriptions, were considered as part of the type series for that species. Males were associated based on position with females in the collection, identical collection labels, and comparison with original descriptions. Redescriptions of the species are based on all specimens considered to form the type series. Observations were made using a fiber optic illuminator and a Nikon SMZ-U stereo microscope. Specimens were photographed with a Leica DC500 digital camera attached to a Leica Z16 APO macroscope and the serial images obtained combined with Auto Montage. 
Type specimens of A. splendens Nikol'skaya, 1952 (Canadian National Collection of Insects, Arachnids \& Nematodes, Ottawa) and A. formosanus Crawford, 1913 (United States National Entomological Collection, Washington, D.C.) were also examined for comparison.

Terms for structure follow Gibson $(1995,1997,2011)$ and Gibson \& Fusu (2016); terms for sculpture mostly follow Gibson $(2009,2011)$ and Gibson \& Fusu (2016), but the term imbricate is used sensu Harris (1979), and reticulate-imbricate and coriaceous-imbricate sensu Gibson \& Fusu (2016) are not differentiated.

Measurements for structure follow Gibson (1989). A Nikon SMZ-U microscope fitted with a $14 \mathrm{~mm}$ ocular grid having 140 divisions was used for measurements. Fore wings of females and males were all taken at a magnification of 60; antennae, distance between ocelli and inner orbit measurements were taken at a magnification of 100 .

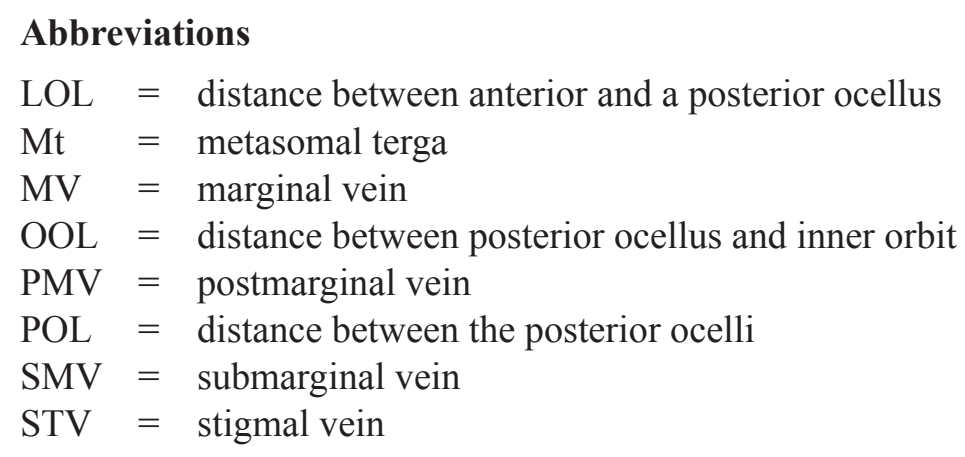

\section{Results}

Class Hexapoda Blainville, 1861

Order Hymenoptera Linnaeus, 1758

Superfamily Chalcidoidea Latreille, 1817

Family Eupelmidae Walker, 1833

Subfamily Eupelminae Walker, 1833

Genus Anastatus Motschulsky, 1859

\section{Key to species of Anastatus described by J.K. Sheng and coauthors from China}

1. Brachypterous, apex of fore wing extending to no more than middle of gaster (Figs 32, 34) ......... 2

- Macropterous, apex of fore wing extending at least to apex of gaster (Figs 8, 41) ......................... 3

2. Fore wing very short, extending to no more than apex of second gastral tergite (Fig. 34); mesoscutum with anterior convex portion of medial lobe rhomboidal (Fig. 38)

A. meilingensis Sheng \& Yu, 1998

- Fore wing extending to middle of gaster (Figs 28, 32); mesoscutum with anterior convex part of medial lobe almost triangular (Fig. 31) A. huangi Sheng \& Yu, 1998

3. Profemur ventrally expanded into blunt to sharp angulation (tooth) at apical quarter (Figs 7, 47); mesoscutum with anterior convex portion of medial lobe densely setose and posterior concave portion with metallic green luster (Figs 4, 45)

- Profemur with ventral margin not angularly expanded (Fig. 36); mesoscutum with anterior convex portion of medial lobe with a few setae (Figs 8,24) and posterior concave portion with metallic bluish-purple luster 
4. Profemur ventroapically expanded into an acute, tooth-like angulation (Fig. 7); lower face with a few setae (Fig. 3); scrobal depression with scrobes shallow, not distinctly delimited in upper half (Fig. 5) A. dexingensis Sheng \& Wang, 1997

- Profemur ventroapically expanded into a blunt angulation (Fig. 47); lower face densely setose (Figs 42, 46); scrobal depression with scrobes deep, distinctly delimited (Fig. 46)

A. shichengensis Sheng \& Wang, 1997

5. Mesosoma dark (Fig. 24); fore wing disc with basal infuscate part three times as wide as hyaline cross-band (Fig. 23); scrobal depression not distinctly delimited in upper third, but separated from anterior ocellus by $0.8-1.1 \times$ diameter of ocellus (Fig. 20). Male with antennal clava as long as the apical four funiculars or longer

A. fulloi Sheng \& Wang, 1997

- Mesosoma yellowish-brown (Fig. 9); fore wing disc with basal infuscate part twice as wide as hyaline cross-band (Fig. 10); scrobal depression distinctly delimited, including upper third, separated from anterior ocellus by about 1.5-2.0 $\times$ diameter of ocellus (Fig. 12). Male with antennal clava as long as the apical three funiculars, much shorter than the apical four funiculars

A. flavipes Sheng \& Wang, 1997

Anastatus dexingensis Sheng \& Wang, 1997

Figs $1-7$

Anastatus dexingensis Sheng \& Wang in Sheng et al., 1997: 59-60, figs 6-9.

\section{Original type material designated}

\section{Holotype}

CHINA: + , Dexing, Jiangxi Prov., Jun. 1984, YU Yunxiang leg.

\section{Paratypes}

CHINA: 4 q , same data as holotype.

\section{Redescription}

Female (Figs 1-7)

LENGTH. $2.5-3 \mathrm{~mm}$.

CoLor. Head dark with metallic purple luster on frons and temple, gena and occiput metallic green; ocelli dark brown; maxillary and labial palpi dark brown to black (Figs 2-3). Antenna (Figs 3, 5) with scape yellowish-brown and pedicel dark brown with metallic purple luster (flagella missing but presumably dark based on original description). Pronotum (Fig. 4) almost black, with purple and bluishgreen luster under some angles, except median groove dark brown; and posterolateral corner black anterior to spiracle. Mesoscutum (Fig. 4) with anterior convex part of medial lobe black with metallic purple to green luster, posterior concave part with metallic greenish-blue luster; lateral lobe dark with metallic green luster. Scutellar-axillar complex (Fig. 4) black with greenish-blue metallic luster. Tegula, acropleuron and prepectus dark brown (Fig. 6). Front leg (Fig. 7) with coxa and femur dark brown with metallic luster, tibia and basal two tarsomeres dark brown, apical three tarsomeres brown; middle and hind legs dark brown except mesotarsus and apex of metafemur brown. Metanotum and propodeum (Figs 1, 4) dark brown. Gaster (Fig. 1) dark brown to black with base whitish.

HEAD. In frontal view (Fig. 3) about 1.1-1.3 $\times$ wider than high; in dorsal view (Fig. 2) width $2 \times$ length, hind margin concave; in lateral view about $1.85 \times$ higher than long. Eye height $1.67 \times$ eye length in lateral view; distance between eyes below 2.1-2.5 $\times$ distance between eyes above; malar space about $0.43 \times$ eye height; distance between toruli $1.57 \times$ as long as distance between torulus and clypeal edge, 
and $2.4 \times$ distance between torulus and orbit; frontovertex narrower than eye. OOL: POL: LOL $=$ 2.5: 7: 5.5. Vertex and frons reticulate with a few white setae; lower face reticulate-rugose, with dense lanceolate white setae (mostly broken), medially angulate; gena and parascrobal region reticulate; scrobes imbricate; interantennal region imbricate with dense white lanceolate setose. Scrobal depression (Fig. 5) with scrobes shallow and channel-like, with lateral margin carinate ventrally but very weak dorsally, the dorsal margin not clearly delimited but dorsal-most limit of lateral margin $2.3 \times$ diameter of anterior ocellus from ocellus. Lower orbit higher than ventral margin of torulus (Fig. 3). Antenna with relative length (width) of scape $=42(6)$; pedicel 10(5); anellus 5(5).
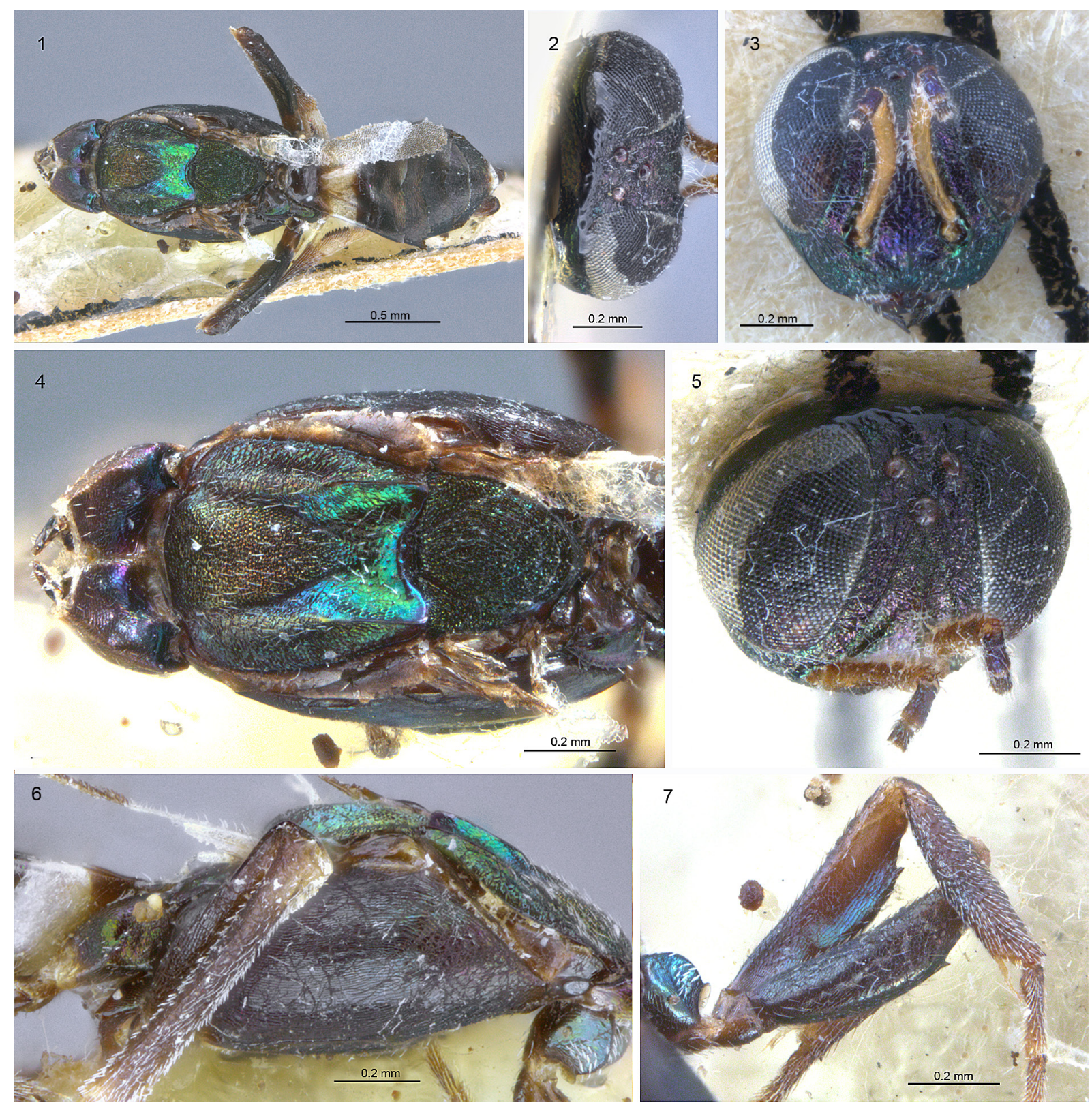

Figs 1-7. Anastatus dexingensis Sheng \& Wang, 1997. 1-6. Holotype, + . 1. Body, dorsal view (wing mostly destroyed, remnants superficially appear like a short wing). 2. Head, dorsal view. 3. Head, frontal view. 4. Mesosoma, dorsal view. 5. Head, frontolateral view. 6. Mesosoma, lateral view. - 7. Paratype, front legs. 
Body. Pronotum (Fig. 4) in dorsal view obtuse-triangular, finely reticulate, concave postero-medially, and with few short setae along anterior margin of collar, only one short seta posteriorly anterior to each spiracle; median groove distinct. Mesoscutum (Fig. 4) with anterior convex part of medial lobe V-shaped with sides almost uniformly convergent posteriorly, $0.76 \times$ total length of mesoscutum, longer than broad, rugose-punctate with posteriorly directed setae, and posterior concave part strongly concave, coriaceous to finely reticulate, with some white hair-like setae; lateral lobe with inclined inner surface finely reticulate to strongly reticulate posteriorly. Scutellar-axillar complex (Fig. 4) convex, coarsely punctate-reticulate, scutellum $1.5 \times$ longer than broad. Acropleuron (Fig. 6) with anterior one-third finely reticulate and with few short setae, posterior two-thirds finely strigose. Macropterous, fore wing (Fig. 1) mostly missing, but apex extending beyond gaster (based on original description); basal plate bare; basal cell sparsely setose with thinner translucent setae than setae on disc; costal cell broken; submarginal vein with a row of six white setae; remaining part of disc with light brown infuscation and densely setose with thick light-brown setae except for white setae of hyaline cross-band; hyaline crossband not extending to junction of MV and STV, presumably curved; SMV: MV: PMV: STV = 33: 23: 11: 6 (paratype).

LeGs. Profemur (Fig. 7) with ventral margin evenly arched basally, but with a sharp, tooth-like angulation in apical quarter. Middle leg with spur as long as basitarsus; tibia with apical pegs in a patch; basal four tarsomeres with black pegs on each side. Hind leg with basitarsus as long as following three tarsomeres combined.

GASTER (Fig. 1). Shorter than mesosoma; ovipositor sheath not exserted.

\section{Notes}

Of the original type material, only one labeled female and one unlabeled female were found. The labeled female, here considered to be the holotype, has three labels: "Dexing, Jiangxi, host: egg of Dendrolimus kikuchii", "1984, YU Yunxiang”, and "Anastatus dexingensis sp. nov. Det. Sheng Jinkun". The holotype lacks both antennae beyond the pedicels, the left protibia, the left protarsus, both left wings and the right hind wing; the right fore wing is only partially preserved. The unlabeled female, here considered to be a paratype, lacks both antennae beyond the anelli, the hind wings, the front legs (lost accidently when the first author examined the specimen), the right protibia and protarsus; both fore wings are only partially preserved.

\section{Remarks}

The most important characters of females of this species are as follows: 1) profemur ventrally with a sharp tooth at apical quarter (Fig. 7) (not at apical third as stated in original description); 2) scrobal depression with scrobes shallow, lateral margin very weak dorsally (Fig. 5); 3) mesoscutum with less setae and with a different pattern (Fig. 4) than for A. shichengensis (Fig. 45), and with anterior convex part of medial lobe V-shaped; 4) posterior concave part of mesoscutum very short, only one-quarter the length of the scutellum (Fig. 4). The paratype originally had its left front leg, and the tooth of the profemur was clearly evident, but the leg was lost accidently when the first author examined the specimen. In the key of Kalina (1981), A. dexingensis keys out to A. splendens, but in A. splendens the posterior concave part of mesoscutum is as long as the scutellum (Nikol'skaya 1952), and the profemur is not toothed. 
PENG L. et al., Sheng Chinese Anastatus species redescription

Anastatus flavipes Sheng \& Wang, 1997

Figs 8-18

Anastatus flavipes Sheng \& Wang in Sheng et al., 1997: 60-61, figs 10-13.

\title{
Original type material designated
}

\section{Holotype}

CHINA: + , Dexing, Jiangxi Prov., 15 Jun. 1984, YU Jingting leg.

\author{
Allotype \\ CHINA: $\hat{\jmath}$, same data as holotype. \\ Paratypes

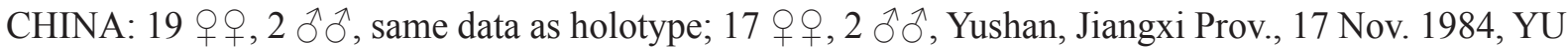 \\ Yunxiang leg.; 2 q , Xinjian, Jiangxi Prov., 19 Jul. 1980, SHENG Jinkun leg.; 2 + $ᄋ$, LianTang, Jiangxi \\ Prov., 10 Jul. 1955, ZHANG Shangmei leg.; 11 qq, 3 ๙ิ ô, Xintai, Shandong Prov., Jul. 1987, FAN Di

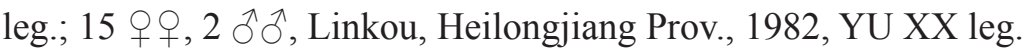

\section{Redescription}

Female (Figs 8-14)

Length. About 2.1-2.9 mm.

Color. Head (Figs 9, 11-12) dark with metallic purple luster on frons and occiput; temple, gena and lower face with slight purple-green luster; ocelli brown, maxillary and labial palpi dark brown to black. Antenna (Fig. 13) with scape yellowish-brown, pedicel brownish-black with metallic bluish-green luster, flagellum brownish-black. Pronotum (Fig. 8) yellowish-brown with purple luster under some angles, and posterolateral corner black anterior to spiracle. Mesoscutum (Fig. 8) with anterior convex part of medial lobe metallic golden-green, posterior concave part brown with metallic blue luster; lateral lobe yellowish-brown with metallic purple luster. Scutellar-axillar complex (Figs 8, 10) metallic golden greenish-blue. Tegula, acropleuron and prepectus yellowish-brown (Fig. 9). Front leg (Fig. 9) with coxa and femur brown, tibia and tarsus yellowish-brown; middle and hind legs (Fig. 9) with coxae, femora and tibiae dark brown, tarsi yellowish-brown. Metanotum and propodeum (Fig. 10) yellowish-brown. Gaster black with base yellowish-brown.

HEAD. In frontal view (Fig. 12) about 1.2-1.4 $\times$ wider than high; in dorsal view (Fig. 11) width about 2.2-2.5 $\times$ length, hind margin slightly concave; in lateral view (Fig. 9) about 1.6-2.1 $\times$ higher than long. Eye height about $1.7 \times$ eye length in lateral view; distance between eyes below $2-2.4 \times$ distance between eyes above, malar space $0.36-0.5 \times$ eye height, distance between toruli $1.3 \times$ distance between torulus and clypeal edge, and $1.7 \times$ distance between torulus and orbit; frontovertex wider than eye. OOL: POL: $\mathrm{LOL}=4: 10-10.3: 6$. Vertex and frons reticulate; lower face (Fig. 12) coarsely reticulate and with dense white hair-like setae, medially angulate; gena finely reticulate; parascrobal region and scrobe reticulate, interantennal region reticulate-punctate with sparsely white hair-like setae. Scrobal depression (Fig. 12) with scrobes shallow, channel-like, lateral margin carinate ventrally and weakly carinate dorsally, the dorsal margin separated from anterior ocellus by 1.5-2.0 $\times$ diameter of ocellus. Lower orbit higher than ventral margin of torulus (Fig. 12). Antenna (Fig. 13) with relative length (width) of scape $=39-42(7)$; pedicel 9(5); anellus 4(5); $1^{\text {st }}$ to $7^{\text {th }}$ funiculars: 9.5-10.4(5): 8-8.4(5): 8.6-9(5.5): 8(6.5): 9(8): 9(9): 9(9); clava $21-23(11)$. 

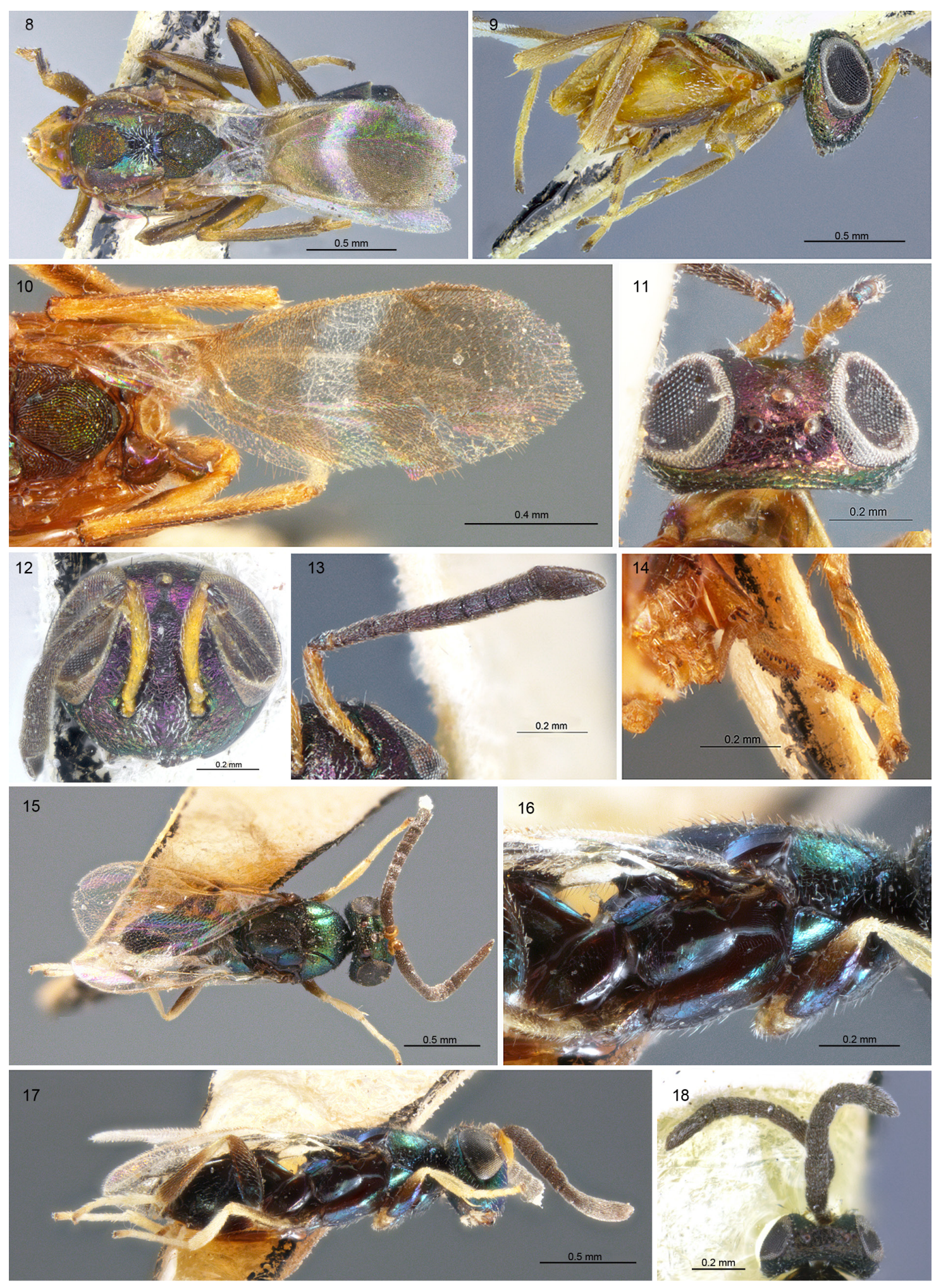

Figs 8-18. Anastatus flavipes Sheng \& Wang, 1997. 8, 12-13. Holotype, + . 9-11, 14. Paratype, $q .-$ 8. Body, dorsal view. 9. Body, lateral view. 10. Scutellar-axillar complex and fore wing. 11. Head, dorsal view. 12. Head, frontal view. 13. Antenna. 14. Apex of mesotibia and mesotarsus. 15-18. Allotype, ふึ. 15. Body, dorsal view. 16. Mesosoma, lateral view. 17. Body, lateral view. 18. Antennae. 
BoDy. Pronotum in dorsal view (Fig. 8) acute-triangular and finely coriaceous, concave postero-medially, with a line of short setae along anterior margin of collar, two long setae and three short setae posteriorly anterior to each spiracle; median groove distinct. Mesoscutum (Fig. 8) with anterior convex part of medial lobe shield-like with sides subparallel basally and abruptly convergent apically, about $0.6 \times$ total length of mesoscutum, longer than broad, coarsely punctulate and bare, but posterior concave part strongly concave, smooth to finely reticulate, with long white setae in a radial pattern; lateral lobe inclined and reticulate. Scutellar-axillar complex (Figs 8, 10) convex, coarsely punctate-reticulate, scutellum 1.25$1.3 \times$ longer than broad. Acropleuron (Fig. 9) with anterior one-third finely reticulate and densely setose with white hair-like setae, posterior two-thirds finely strigose. Macropterous; fore wing (Fig. 10) 0.8 $1.1 \mathrm{~mm}$ in length, about $3 \times$ as long as wide, with apex rounded and extending beyond gaster; basal plate with a row of three dark setae; basal cell sparsely setose with thinner setae than setae of disc; costal cell ventrally with patch of setae at basal one-third, and dorsally bare along length; submarginal vein with a row of six white setae; disc with orangey-brown infuscation basally and apically of hyaline cross-band behind MV except about apical one-fifth more hyaline along wing margin, with basally infuscate region $2.2 \times$ wider than hyaline cross-band; disc densely setose with comparatively thick orangey-brown setae except for white setae of hyaline cross-band, apical more hyaline region with setae slightly thinner than infuscate region; hyaline cross-band curved and extending to junction of MV and STV; SMV: MV: PMV: STV = 33-36: 30-31: 15: 6-7.

Legs. Profemur (Fig. 8) with ventral margin evenly arched, not toothed. Middle leg (Fig. 9) with spur as long as basitarsus; tibia with apical pegs in a patch; basal four tarsomeres with black pegs on each margin. Hind leg with basitarsus as long as following two tarsomeres combined.

GASTER. Shorter than mesosoma (Fig. 8); ovipositor sheath slightly exserted.

Male (Figs 15-18)

LENGTH. About 1.7-2.1 mm.

Color. Head (Figs 15, 17-18) metallic green to dark metallic blue; ocelli brown to dark brown; eyes dark brown; antenna (Figs 15, 18) dark brown with scape yellowish-brown. Mesosoma (Fig. 15) similar in color to head. Front leg (Figs 15, 16) with trochanter metallic blue, femur dark brown except apex, tibia and tarsus light brown; middle leg brown, except base of tibia and tarsus pale brown; hind leg pale brown except trochanter dark brown. Gaster (Figs 15, 17) dark brown to black.

HEAD. In frontal view about 1.2-1.9 $\times$ higher than wide; in dorsal view (Fig. 18) $1.6-1.8 \times$ wider than long; in lateral view 1.5-1.6 $\times$ higher than long. Eye height about $1.3 \times$ eye length in lateral view; distance between eyes below $1.5 \times$ distance between eyes above, malar space $0.4 \times$ eye height, distance between toruli and clypeal edge 1.2-1.5 $\times$ distance between torulus, and $1.8 \times$ distance between torulus and orbit; frontovertex much wider than eye (Fig. 18). OOL: POL: LOL = 3: 12: 6. Scrobal depression with scrobes shallow and channel-like, lateral margin very near anterior ocellus, separated by about $0.3 \times$ diameter of anterior ocellus. Lower orbit lower than ventral margin of torulus. Antenna (Fig. 18) with scape ovoid, about 2.4-2.6 $\times$ as long as maximum width; pedicel subglobular, almost as long as wide; flagellum densely setose; length of pedicel + flagellum about 1.5-1.8 $\times$ head width; each funicular and clava length: 14-20: 14-18: 12-17: 8-11: 8-13: 7-11: 7-9: 23-26; some specimens with $7^{\text {th }}$ funicular wider than long; clava as long as apical three funiculars but much shorter than apical four funiculars. Vertex and frons coriaceous and setose, lower face reticulate and with translucent short hairlike setae, gena slightly angulate.

Body. Mesosoma (Fig. 15) with mesoscutum reticulate and setose, scutellar-axillar complex (Fig. 15) with axillae alutaceous to reticulate, scutellum reticulate. Fore wing (Fig. 15) hyaline, about $1.1 \mathrm{~mm}$ in length, $1.9 \times$ as long as wide, apex rounded and extending beyond gaster; basal plate with four dark 
setae; basal cell sparsely setose with thinner setae than setae of disc; costal cell ventrally with a row of setae, and dorsally bare; submarginal vein with a row of light brown setae; disc uniformly setose with pale setae; SMV: MV: PMV: STV = 24-26: 13-15: 10-11: 8-9.

\section{Notes}

Of the original type material, 18 specimens were found that resemble the original description and illustrations provided for A. flavipes. One labeled female in good condition, here considered to be the holotype, has two labels: "Shangrao, Jiangxi Prov., host: egg of Dendrolimus kikuchii (Drury)", and "15-25 June 1984, YU Jingting". One labeled male in good condition, here considered to be the allotype, has two labels the same as the holotype. Other specimens considered as paratypes: 6 우 $0,4 \hat{\delta} \hat{o}$, Dexing (part of Shangrao City) or Shangrao, Jiangxi Prov., 15-25 June 1984, YU Jingting; 1 ô, Yushan, Jiangxi Prov., 17 Nov. 1984, YU Jingting; 1 ㅇ, Liantang, Jiangxi Prov., early August 1955; 4 우, Xintai, Shandong Prov., July - August 1987, FAN Di. All the specimens from Heilongiiang Province were destroyed. The label dates of the 12 specimens from Dexing and Shangrao labeled by Sheng are in conflict with the published data. We suspect that 15 June is abbreviated for 15-25 June.

\section{Remarks}

Females of A. flavipes resemble those of A. fulloi, but the body is yellowish-brown (Fig. 9) rather than metallic green (Fig. 24); scrobal depression with lateral margin not distinct dorsally, but about 1.5-2.0 $\times$ diameter of ocellus from anterior ocellus (Fig. 12) rather than $0.8-1.10 \times$ diameter of ocellus from anterior ocellus (Fig. 20); and fore wing with basal infuscate setose region about $2.2 \times$ wider than hyaline cross-band (Fig. 10) rather than $3 \times$ wider than hyaline cross-band behind MV (Fig. 23). Males differ from those of $A$. fulloi by the antennal clava being as long as the apical three funiculars, much shorter than the apical four funiculars (Figs 15, 18). In the key of Kalina (1981), females of A. flavipes key out to A. formosanus, but in A. formosanus the lateral margins of the scrobal depression reach the anterior ocellus, the frontovertex is as wide as an eye, and the anterior convex part of the medial lobe is $0.78 \times$ the total length of the mesoscutum.

Anastatus fulloi Sheng \& Wang, 1997

Figs 19-27

Anastatus fulloi Sheng \& Wang in Sheng et al., 1997: 61-62, figs 14-15.

\section{Original type material designated}

\section{Holotype}

CHINA: , Mt. Wuyi, Jiangxi Prov., 16 Jul. 1980, SHENG Jinkun leg.

\section{Allotype}

CHINA: $\hat{\jmath}$, same data as holotype.

\section{Paratypes}

CHINA: 16 우, 5 $\widehat{\partial}$, same data as holotype; 9 우, 1 ठ, Xinjian, Jiangxi Prov., 30 Sep. 1991, ZHAO Fengxia leg.; 3 우, Xinjian, Jiangxi Prov.,WANG Guohong leg.

\section{Redescription}

Female (Figs 19-24)

LeNGTH. About 2.2-3 mm.

CoLor. Head (Figs 19-21) dark with coppery-green metallic luster on, gena, temple and occiput, and frons with metallic purple luster; ocelli light brown, maxillary and labial palpi dark brown to black. Antenna (Figs 21-22) with scape brown, pedicel brownish-black with metallic bluish-green luster, 
flagellum brownish-black. Pronotum brown with purple luster under some angles, and posterolateral corner black anterior to spiracle. Mesoscutum (Fig. 24) with anterior convex part of medial lobe metallic golden reddish-green, posterior concave part dark brown with coppery green metallic luster; lateral lobe brown with metallic purple luster. Scutellar-axillar complex (Fig. 24) metallic green to purple. Tegula and prepectus brown, acropleuron dark brown with metallic purple luster. Legs mostly dark brown, tarsi, tibiae apically, and knees brown. Metanotum and propodeum dark brown. Gaster (Fig. 23) black with base yellowish-brown.

HEAD. In frontal view (Fig. 19) about 1.3-1.4 $\times$ wider than high; in dorsal view (Fig. 21) width about 1.9-2 $\times$ length, hind margin slightly concave; in lateral view about $1.6 \times$ higher than long. Eye height $1.44 \times$ eye length in lateral view; distance between eyes below 2.1-2.4 $\times$ distance between eyes above; malar space about $0.4 \times$ eye height; distance between toruli slightly greater than distance between torulus and clypeal edge, and $2 \times$ distance between torulus and orbit; frontovertex as wide as eye. OOL: POL: $\mathrm{LOL}=4:$ 10-11: 6-7. Vertex longitudinally alveolate, frons coriaceous; lower face slightly alveolate with dense white hair-like setae, medially angulate; gena longitudinally alveolate; parascrobal region strigate ventrally and coriaceous dorsally, scrobes reticulate, interantennal region (Fig. 19) reticulate and with dense white lanceolate setae. Scrobal depression with scrobe (Fig. 20) shallow, channel-like, with lateral margin carinate ventrally and weakly carinate dorsally; dorsal margin separated from anterior ocellus by $0.8-1.1 \times$ diameter of ocellus. Lower orbit higher than ventral margin of torulus (Fig. 19). Antennal relative length (width) of scape $=43-46(9)$; pedicel 12(6); anellus $3.5(6) ; 1^{\text {st }}$ to $7^{\text {th }}$ funiculars: 11(7): 10(8): 10-11(9): 7-9(9): 7-9(9): 7-9(9.5): 7(9-10); clava 21-24(10-13).

Body. Pronotum in dorsal view acute-triangular, smooth to very finely coriaceous, concave posteromedially and bare at anterior margin of collar, one long seta and four short setae posteriorly anterior to each spiracle; with distinct median groove. Mesoscutum (Fig. 24) with anterior convex part of medial lobe shield-like with sides subparallel basally and abruptly convergent apically, $0.75 \times$ total length of mesoscutum, longer than broad, coarsely punctate-reticulate and bare, but posterior concave part strongly concave, smooth to reticulate, with white long setae in a radial pattern; lateral lobe inclined and imbricate. Scutellar-axillar complex (Fig. 24) convex, coarsely punctate-reticulate, scutellum 1.1-1.2 $\times$ as long as broad. Acropleuron with anterior one-third finely coriaceous and with translucent short hair-like setae, posterior two-thirds finely strigose. Macropterous; fore wing (Fig. 23) $1.7 \mathrm{~mm}$ in length, about $3 \times$ as long as wide, with apex rounded and extending beyond gaster; basal plate with a row of five dark setae; basal cell sparsely setose with thinner setae than setae of disc; costal cell ventrally with a row of setae along length, and dorsally bare; submarginal vein with a row of seven white setae; disc with brownish infuscation basally and apically of hyaline cross-band behind MV except about apical one-fifth slightly more hyaline along wing margin, with basally infuscate region $3 \times$ wider than hyaline cross-band; disc densely setose with comparatively thick brown setae except for white setae of hyaline cross-band; hyaline cross-band curved, not extending to junction of MV and STV; SMV: MV: PMV: STV= 32-35: 27-29: 12-15: 5-6.

Legs. Profemur with ventral margin evenly arched, not toothed. Middle leg with spur as long as basitarsus, tibia with pegs in a patch; basal four tarsomeres with black pegs on each side. Hind leg with basitarsus as long as following three tarsomeres combined.

GASTER. Shorter than mesosoma, ovipositor sheath exserted for distance slightly shorter than length of syntergum.

Male (Figs 25-27)

LENGTH. About $1.7-1.9 \mathrm{~mm}$. 

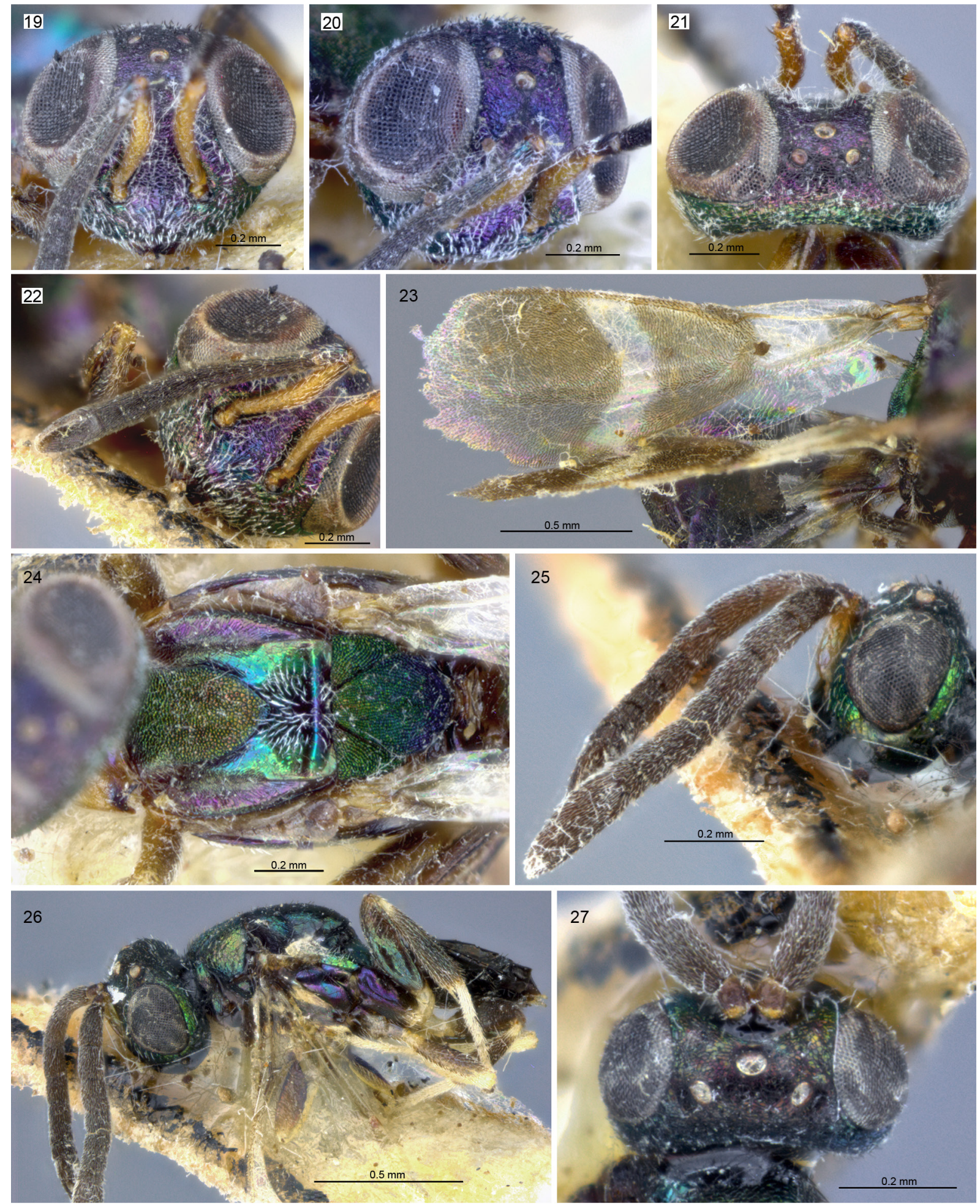

Figs 19-27. Anastatus fulloi Sheng \& Wang, 1997. 19-24. Holotype, ๆ. 25-27. Allotype, ô. - 19. Head, frontal view. 20. Head, frontolateral view. 21. Head, dorsal view. 22. Antennae. 23. Fore wing. 24. Mesonotum. 25. Antennae. 26. Body, lateral view. 27. Head, dorsal view. 
Color. Body (Figs 26, 27) dark with greenish-blue metallic luster except vertex, face and gena metallic purplish-green; ocellus (Fig. 27) light brown; eyes black; antennae dark brown. Mesosoma similar in color to head (Fig. 26). Front leg (Fig. 26) brown with tibia and tarsi light brown to white; middle leg brown with apex of femur, tibia and tarsi light yellowish-brown; hind leg with femur dark brown with greenish-blue metallic luster, tibia dark brown, tarsi light yellowish-brown. Gaster black (Fig. 26).

HEAD. In frontal view about 1.1-1.2 $\times$ wider than high; in dorsal view (Fig. 27) about 2.0-2.3 $\times$ wider than long; in lateral view 1.6-1.7 $\times$ higher than long. Eye height about $1.3 \times$ eye length in lateral view; distance between eyes below $1.5 \times$ distance between eyes above; malar space $0.4 \times$ eye height; distance between torulus and clypeal edge 1.2-1.5 $\times$ distance between toruli, and $1.8 \times$ distance between torulus and orbit. OOL: POL: LOL $=2: 8-11: 4-5$. Scrobal depression with scrobes shallow and channellike, lateral margin extending to anterior ocellus. Lower orbit slightly lower than ventral margin of torulus. Antenna (Fig. 25) with scape ovoid, about $2.3 \times$ as long as maximum width; pedicel (Fig. 27) subglobular, as long as wide, flagellum densely setose; length of pedicel + flagellum about $1.7 \times$ head width; each funicular and clava length: $15: 11-12: 11: 9: 8: 6-7: 4-5: 29 ; 6^{\text {th }}$ and $7^{\text {th }}$ funiculars wider than long; clava as long as apical four flagellomeres or longer. Vertex (Fig. 27) coriaceous with short brown setae, frons coriaceous, lower face reticulate with short translucent hair-like setae, gena slightly angulate.

Body. Mesosoma with mesoscutum reticulate and setose, scutellar-axillar complex with axillae alutaceous to reticulate, scutellum reticulate. Fore wing hyaline, about $1.1 \mathrm{~mm}$ in length, $1.8 \times$ as long as wide, apex rounded and extending beyond gaster; basal plate with one dark setae; basal cell almost bare, but with several thinner setae scattered throughout cell; costal cell ventrally with a row of setae, and dorsally bare; submarginal vein with a row of light brown setae; disc sparsely setose with pale setae; SMV: MV: PMV: STV = 32-34: 19-20: 11-12: 7-8.

\section{Notes}

Of the original type material, 16 specimens were found that resemble the original description and illustrations provided for A. fulloi. One female labeled with "Anastatus fulloi", here considered to be the holotype, has another two labels: "Meiling, Jiangxi Prov. host: Erthesina fullo (Thunberg)", and "5 July 1980, Sheng Jinkun". One male in good condition, here considered to be the allotype, has two labels: "Mt. Wuyi, Jiangxi Prov." and "10 July 1980, SHENG Jinkun". Other specimens considered as paratypes: 1 q, Mt. Wuyi, Jiangxi Prov., 10 July 1980, SHENG Jinkun; 3 + $q$, Meiling, Jiangxi Prov., 10 July 1980, SHENG Jinkun; 5 우, 1 , Meiling, Jiangxi Prov., 5 July 1980, SHENG Jinkun; 2 우, Meiling, Jiangxi Prov., 19 July 1980, SHENG Jinkun; 1 , Xinjian, Jiangxi Prov., 30 September 1991, ZHAO Fengxia.

Associated with these specimens are five leaf-remnants with attached egg shells collected on 5 July 1980. All the specimens were in one box in mixed series; we did not find any specimen from Mt. Wuyi collected on 16 July 1980. The specimens from Mt. Wuyi have handwritten labels, but the specimens from Meiling have a printed locality label and a written date label. It seems Sheng incorrectly labeled the Meiling specimens because he could not be in two such widely distant places (Mt. Wuyi is more than $300 \mathrm{Km}$ from Meiling) in one day (10 July 1980). We suspect that he collected the bug egg masses on 5 July 1980, and the eupelmids then emerged successively.

\section{Remarks}

Females most closely resemble A. flavipes and key out to A. formosanus using Kalina (1981), but can be differentiated by the features discussed under the latter species. Males have the clava as long as the apical four funiculars or longer (Fig. 25) whereas males of A. flavipes have the clava as long as apical three funiculars but much shorter than the apical four funiculars (Figs 15, 17). 
Anastatus huangi Sheng \& Yu, 1998

Figs $28-33$

Anastatus huangi Sheng \& Yu, 1998: 6-7, fig. 2.

\title{
Original type material designated
}

\section{Holotype}

CHINA: +, Wannian, Jiangxi Prov., 15 Jun. 1996, YU Yunxiang leg.

\author{
Allotype \\ CHINA: $\widehat{\partial}$, same data as holotype. \\ Paratypes \\ CHINA: 5 우, $4 \lesssim \precsim$, same data as holotype.
}

\section{Redescription}

Female (Figs 28-33)

LENGTH. $1.9 \mathrm{~mm}$.

Color. Head (Figs 28-30) dark with metallic purple luster on temple and occiput, and lower face and gena mainly with metallic green luster; ocelli dark brown; maxillary and labial palpi brown to dark brown. Antenna (Fig. 30) with scape yellowish-brown and pedicel dark brown with metallic green luster, flagellum dark brown. Pronotum (Fig. 31) brownish-yellow, and posterolateral corner dark brown anterior to spiracle. Mesoscutum (Fig. 31) light yellowish-brown except anterior convex part of medial lobe with golden-green metallic luster. Scutellar-axillar complex (Figs 31, 32) brown with goldengreen metallic luster. Tegula, acropleuron and prepectus light yellowish-brown (Fig. 28). Legs (Fig. 33) yellowish-brown except tibiae light yellowish-brown. Metanotum and propodeum (Fig. 32) brown with margins slightly darker. Gaster (Fig. 28) dark brown with base pale yellow.

HeAd. In frontal view (Fig. 30) about $1.27 \times$ wider than high; in dorsal view width $1.4 \times$ length, hind margin concave; in lateral view about $1.2 \times$ higher than long. Eye height $1.71 \times$ eye length in lateral view, distance between eyes below $2.1 \times$ distance between eyes above; malar space $0.45 \times$ eye height; distance between toruli $0.9 \times$ distance between torulus and clypeal edge, and $1.29 \times$ distance between torulus and orbit; frontovertex as wide as eye. OOL: POL: $L O L=2: 9: 5$. Vertex (Fig. 29) reticulate, frons imbricate; lower face (Fig. 30) coarsely reticulate-rugose with short translucent hair-like thin setae, medially angulate; gena strigose; parascrobal region reticulate-rugose to coriaceous upper portion, scrobes and interantennal region (Fig. 30) reticulate-rugose, interantennal region with some white slender lanceolate setae. Scrobal depression (Fig. 29) with scrobe deep, lateral margin angulate, separated from anterior ocellus by distance $1.6 \times$ diameter of anterior ocellus. Lower orbit in line with ventral margin of torulus. Antenna (Fig. 30) with scape not extending to anterior ocellus, relative length (width) of scape 31(6); pedicel 9(5); anellus 3(4); $1^{\text {st }}$ to $7^{\text {th }}$ funiculars: $8(5): 8(5): 7(6): 7.5(7): 7.5(7.5): 6(8): 6(8)$; clava 21(9).

Body. Pronotum in dorsal view acute-triangular, very finely coriaceous, concave postero-medially, four short setae at anterior margin of collar and only one seta posteriorly anterior to each spiracle; median groove shallow. Mesoscutum (Fig. 31) with anterior convex part of medial lobe V-shaped, about $0.64 \times$ total length of mesoscutum, coarsely punctate-reticulate and slightly convex, but posteriorly concave part smooth and shiny, with white long setae directed laterally; lateral lobe inclined and finely reticulate. Scutellar-axillar complex (Fig. 32) convex, longitudinally coarsely reticulate; scutellum $1.63 \times$ longer than wide. Acropleuron (Fig. 28) with fine longitudinally aligned coriaceous sculpture, anterior portion almost bare. Brachypterous; fore wing (Fig. 32 ) about $0.6 \mathrm{~mm}$ in length, $4 \times$ as long as 
wide, with apex rounded and extending to middle of gaster; basal plate with one dark brown seta; basal cell sparsely setose with much thinner setae than setae of disc; costal cell ventrally with few setae, and dorsally bare; disc with dark setae and brownish infuscation basally and apically of posteriorly tapered hyaline cross-band with much thinner white setae behind marginal vein; SMV extending half-length of wing, MV slightly shorter than submarginal vein, STV and PMV absent.

LEGs. Profemur with ventral margin evenly arched, without tooth. Middle leg (Fig. 33) with spur as long as basitarsus; tibia with apical pegs in a patch, basal four tarsomeres with black pegs on each margin. Hind leg (Fig. 33) with basitarsus as long as following four tarsomeres combined.

GASTER (Fig. 28). Shorter than mesosoma; ovipositor sheath exserted for distance equal to length of syntergum.
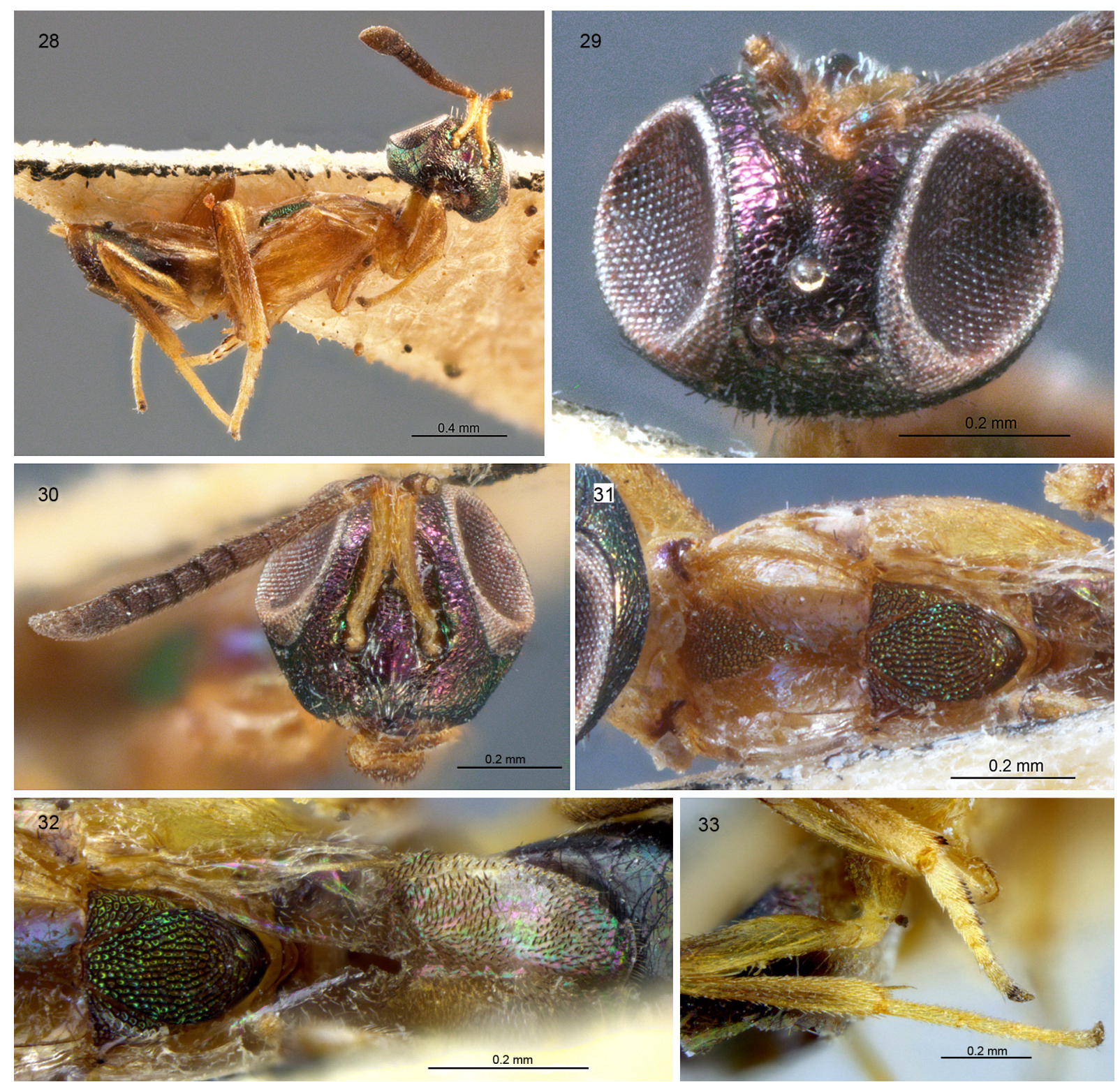

Figs 28-33. Anastatus huangi Sheng \& Yu, 1998, holotype, ‥ 28. Body, lateral view. 29. Head, frontodorsal view. 30. Head, frontal view. 31. Mesosoma, dorsal view. 32. Scutellar-axillar complex and fore wing, dorsal view. 33. Middle and hind legs. 


\title{
Notes
}

Only one unlabeled female, here interpreted as the holotype, was found that resembles the original description and illustrations provided for A. huangi. This specimen is entire except for its left funicle and clava.

\section{Remarks}

The most important characters of females of this species are as follows: 1) head in dorsal view with width $1.43 \times$ length; 2) clava slightly longer than the length of apical three funiculars (Fig. 30); 3) fore wing only extending to middle of gaster (Fig. 28); 4) mesoscutum with anterior convex part of medial lobe triangular, $0.64 \times$ total length of mesoscutum (Fig. 31). Females resemble those of A. meilingensis, but are differentiated by the characters discussed under the latter species. In the key of Kalina (1981), A. huangi keys out to A. brevipennis Ashmead, 1904 and A. gastropachae Ashmead, 1904. However, females of $A$. brevipennis have the head in dorsal view $1.84 \times$ as wide as long and the clava is shorter than the total length of the apical three funiculars (Kalina 1981), whereas in A. gastropachae the anterior convex part of the medial lobe of mesoscutum is $0.56 \times$ the total length of the mesoscutum and the head in dorsal view is $1.96 \times$ as wide as long (Kalina 1981).

\section{Anastatus meilingensis Sheng \& Yu, 1998}

Figs $34-40$

Anastatus meilingensis Sheng \& Yu, 1998: 5-6, fig. 1.

\section{Original type material designated}

\section{Holotype}

CHINA: + , Shangrao, Jiangxi Prov., 15 Jun. 1984, YU Jingting leg.

\author{
Allotype \\ CHINA: $\stackrel{\lambda}{\partial}$, same data as holotype.
}

\section{Paratypes}

CHINA: 28 $q$, same data as holotype; 40 $\uparrow q$, Yushan, Jiangxi Prov., 2-17 May 1984, YU Jingting leg.; 10 우, Meiling, Nanchang, Jiangxi Prov., Jun. 1972, SHENG Jinkun leg.; 3 q $q$, Meiling, Nanchang, Jiangxi Prov., Nov. 1972, SHENG Guangzhuo leg.

\section{Redescription}

Female (Figs 34-40)

LeNGTH. About 2.1-2.9 mm.

Color. Head (Figs 34-37, 40) dark with metallic purple luster on vertex and upper face, and temple, occiput, gena and lower face with metallic green luster; ocelli brown; maxillary and labial palpi dark brown. Antenna (Fig. 36) with scape yellowish-brown, pedicel dark brown with metallic purple luster, flagellum dark brown. Pronotum (Fig. 38) yellowish-brown, with lateral margin posterolateral corner of pronotum anterior to spiracle dark brown. Mesoscutum light yellowish-brown except medial lobe (Fig. 38) with anterior convex part with golden-green metallic luster. Scutellar-axillar complex (Fig. 38) brown with metallic green luster. Tegula and prepectus (Fig. 36) light yellowish-brown, acropleuron (Fig. 36) yellowish-brown. Front leg brownish-yellow, tarsus pale; middle leg yellowish-brown with knee and apex of tibia and tarsus pale; hind leg dark brown except, tarsus light yellow. Metanotum and propodeum dark brown. Gaster (Figs 34,36) dark brown to black with metallic luster under some angles and base partly pale yellow. 
HeAD. In frontal view (Fig. 37) about $1.32 \times$ wider than high; in dorsal view (Fig. 40) width about $2.0 \times$ length, hind margin slight concave; in lateral view (Fig. 36) about $1.55 \times$ higher than long. Eye height $1.57 \times$ eye length in lateral view; distance between eyes below $2.2 \times$ distance between eyes above; malar space about $0.43 \times$ eye height; distance between toruli $1.29 \times$ as long as distance between torulus and clypeal edge, and $1.8 \times$ distance between torulus and orbit; frontovertex narrower than eye. OOL: POL: $L O L=3: 9: 9$. Vertex (Fig. 40) imbricate with several brown hair-like setae, frons coriaceous with white hair-like setae; lower face (Fig. 37) alveolate with short translucent hair-like setae, and medially angulate; gena strigose; parascrobal region and interantennal region rugose, interanternnal region with few translucent hair-like setae. Scrobal depression (Fig. 37) with scrobe alveolate and deep, distinctly delimited ventrally but not distinctly delimited dorsally, separated from anterior ocellus by distance equal to diameter of anterior ocellus. Lower orbit about in line with ventral margin of torulus. Antenna (Fig. 39) with relative length (width) of scape $=35(5)$; pedicel 7(4); anellus 3.5(3.5); $1^{\text {st }}$ to $7^{\text {th }}$ funiculars: 8(4): 9(5): 10(6): 9(6): 8(6.5): 7.5(7): 7(7); clava 18(7.5).
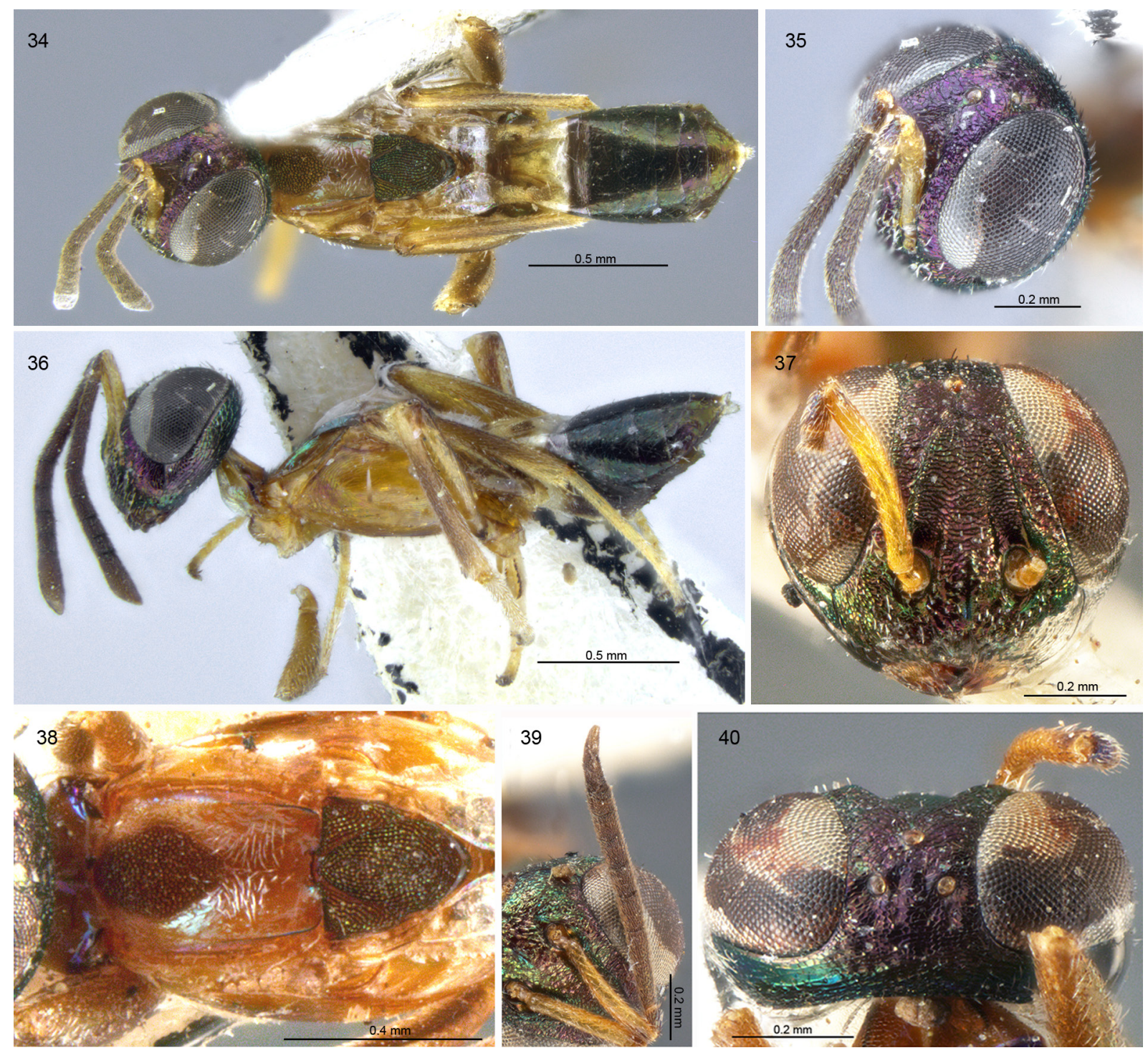

Figs 34-40. Anastatus meilingensis Sheng \& Yu, 1998. 34-36, 39. Holotype, $\uparrow$. 37, 38, 40. Paratype,, . - 34. Body, dorsal view. 35. Head, frontodorsal view. 36. Body, lateral view. 37. Head, frontal view. 38. Mesonotum, dorsal view. 39. Antenna. 40. Head, dorsal view. 
BoDy. Pronotum in dorsal view acute-triangular, concave postero-medially, smooth to very fine coriaceous, with one seta on each side along anterior margin of collar and five setae posteriorly anterior to each spiracle; median groove shallow. Mesoscutum (Fig. 38) with anterior convex medial lobe rhomboidal with sides divergent anteriorly to about middle and convergent over about posterior half, $0.6 \times$ total length of mesoscutum, coarsely punctate-reticulate and slightly convex, and posteriorly concave part smooth and shiny, and with long translucent setae directed laterally; lateral lobe with inclined inner surface shiny, smooth, with translucent setae along outer margin. Scutellar-axillar complex (Fig. 38) convex, longitudinally coarsely reticulate, scutellum $1.6 \times$ longer than broad. Acropleuron (Fig. 36) with fine, longitudinally aligned coriaceous sculpture, anterior one-quarter with several translucent hair-like setae. Brachypterous; fore wing (Fig. 34) about $0.4-0.5 \mathrm{~mm}$ in length, $4 \times$ as long as wide, with apex rounded and extending only slightly over middle of Mt2; basal plate with three dark brown setae; basal cell almost bare, only three or four brown setae apically; costal cell ventrally with four setae at base, and dorsally bare; SMV extending two-thirds length of wing, MV, STV and PMV absent; disc with basal two-thirds hyaline, almost bare, only several hyaline thin setae scattered, and apical one-third with dense yellowish-brown setae, without hyaline cross-band.

Legs (Fig. 36). Profemur with ventral margin evenly arched, without tooth. Middle leg with spur slightly shorter than basitarsus; mesotibia with apical pegs in a patch; basal four tarsomeres with black pegs on each side. Hind leg with basitarsus as long as following three tarsomeres combined.

GASTER (Figs 34, 36). Slightly shorter than mesosoma; ovipositor exserted for distance equal to no more than half length of syntergum.

\section{Notes}

Of the original type material, only four unlabeled females were found that resemble the original description and illustration provided for A. meilingensis. One complete female is here interpreted as holotype of the species. A second female lacks the funicle and clava of both antennae, and left front leg and right metatarsi. The third female lacks the right protarsi, and the fourth female lacks its left antenna, right funicle and clava, and right mesotarsus.

\section{Remarks}

Females of this species resemble those of $A$. huangi, but are differentiated by the following characters: fore wing much shorter, extending only slightly over middle of Mt 2 compared to middle of gaster for A. huangi (cf. Figs 32, 34); fore wing disc with apical one-third densely setose with yellowish-brown setae, without hyaline cross-band compared to fore wing disc of $A$. huangi with thinner brownish setae, and has a tapered hyaline cross-band behind marginal vein; anterior convex medial lobe rhomboidal compared to triangular for $A$. huangi with (cf. Figs 31,38 ); hind leg with basitarsus as long as following three tarsomeres compared to following four tarsomeres in A. huangi (cf. Figs 33, 36). In the key of Kalina (1981), A. meilingensis keys out to A. gastropachae, which is a brachypterous form of $A$. bifasciatus (Geoffroy, 1785) based on the rearings and synonym of Ishii (1938). The original description of A. gastropachae (Ashmead 1904) states that the fore wings are "fuscous, with a transverse band at base and [within] apical third hyaline", whereas A. meilingensis has the basal two-thirds hyaline and the apical one-third with yellowish-brown setae, which is similar to the fore wing color pattern of $A$. meilingensis females. Females of $A$. gastropachae determined in 2015 by L. Fusu in the Canadian National Collection of Insects, Arachnids \& Nematodes (Ottawa) were examined by the senior author. Females have the medial lobe of mesoscutum triangular, the gaster longer than the mesosoma, and the scrobal depression distinctly delimited dorsally compared to A. gastropachae. 
Anastatus shichengensis Sheng \& Wang, 1997

Figs 41-48

Anastatus shichengensis Sheng \& Wang in Sheng et al., 1997: 58-59, figs 1-5.

\title{
Original type material designated
}

\section{Holotype}

CHINA: + , Shicheng, Jiangxi Prov., 1989, LIU Ruiming leg.

\author{
Allotype \\ CHINA: $\hat{\partial}$, same data as holotype. \\ Paratypes \\ CHINA: $9 q \circ$, same data as holotype.
}

\section{Redescription}

Female (Figs 41-48)

LENGTH. 3.5-4 mm.

CoLor. Head (Figs 42, 44, 46) dark with purple metallic luster on frons, and gena, lower face, temple and occiput with metallic green luster; ocelli, maxillary and labial palpi dark brown. Antenna (Figs 42, 44, 46) with scape yellowish-brown, pedicel dark brown to black with metallic purple luster, flagellum dark brown. Pronotum (Fig. 45) dark brown to black, with purple-green luster under some angles, median groove brown, and with posterolateral corner black anterior to spiracle. Mesoscutum (Fig. 45) with anterior convex part of medial lobe dark with golden-purple luster, posterior concave part smooth with metallic green luster, lateral lobe dark with purple luster. Scutellar-axillar (Fig. 45) metallic green. Tegula (Fig. 41) dark brown, prepectus with frontal surface black and lateral surface dark brown, and acropleuron (Fig. 41) black with metallic purple luster within basal anterior quarter. Legs (Fig. 41) dark brown to black except front and middle legs with tibiae and tarsi, and hind leg with tarsus light brown. Metanotum and propodeum black. Gaster (Fig. 41) black with base yellowish-brown.

HEAD. In frontal view (Fig. 42) about $1.3 \times$ wider than high; in dorsal view about $2.2 \times$ wider than long, hind margin concave; in lateral view (Fig. 44) about $1.71 \times$ higher than long. Eye height about $1.78 \times$ eye length in lateral view; distance between eyes below $2.46 \times$ distance between eyes above; malar space $0.43 \times$ eye height; distance between toruli $1.6 \times$ as long as distance between torulus and clypeal edge, and $2 \times$ distance between torulus and orbit; frontovertex much narrower than eye. OOL: POL: LOL $=2-3: 8: 8$. Vertex and frons coriaceous with white setae (Fig. 42); lower face (Fig. 42) punctate with dense long white hair-like pubescence, medially angulate; gena alutaceous; parascrobal region (Figs 42, 46) with lower portion strigose and upper portion coriaceous, interantennal region punctulate and densely setose with white lanceolate setae. Scrobal depression with scrobes (Fig. 46) coriaceous, deep and channel-like, with lateral margin carinate ventrally and weakly carinate dorsally, and separated from anterior ocellus by distance equal to $0.7 \times$ diameter of anterior ocellus. Lower orbit higher than ventral margin of torulus. Antenna with scape extended slightly beyond anterior ocellus; relative length (width) of scape $=54-60(7-8)$; pedicel $11-12(7-8)$; anellus $5(7) ; 1^{\text {st }}$ to $7^{\text {th }}$ funiculars: 15(8): 14-15(8.5): 15(9): 12(10): 11(10): 10(9-10): 9-10(9); clava 30(11).

BoDy. Pronotum (Fig. 45) in dorsal view acute-triangular, coriaceous, concave postero-medially, with five short setae along anterior margin on each side of collar and two long seta and six short setae posteriorly in front of each spiracle, median groove distinct. Mesoscutum (Fig. 45). Anterior convex part of medial lobe U-shaped, $0.66 \times$ total length of mesoscutum, distinctly longer than broad, rugose- 
punctate and densely setose, and posterior portion strongly concave, smooth medially to imbricate laterally, with setae in radial pattern; lateral lobe inclined, imbricate. Scutellar-axillar complex (Fig. 45) convex, coarsely reticulate; scutellum $1.3 \times$ as long as broad. Acropleuron (Fig. 41) imbricate to finely strigose, anterior one-quarter with short white hair-like setae. Macropterous, fore wing (Fig. 43) about 2.2-2.4 mm in length, $2.5 \times$ as long as wide, with apex rounded and extending beyond gaster; basal plate with seven brown setae; basal cell sparsely setose with thinner setae than setae of disc; costal cell ventrally with a row of setae along length, and dorsally bare; submarginal vein with a row more than 12 white setae; disc with brown infuscation basally and apically of hyaline cross-band behind MV except about apical one-fifth more hyaline along wing margin, with basally infuscate setose region $2 \times$ wider than hyaline cross-band; disc densely setose with thick brown setae except for white setae of hyaline cross-band; hyaline cross-band curved, not extending to junction of MV and STV; SMV: MV: PMV: $\mathrm{STV}=53-56: 33-36: 18-19: 9$.

LeGs. Profemur with ventral margin evenly arched basally, but expanded into blunt tooth within apical quarter. Middle leg (Fig. 41) with spur shorter than basitarsus; tibia with apical pegs in a patch; basal four tarsomeres with black pegs on either margin. Hind leg with basitarsus as long as following three tarsomeres combined.

GASTER (Fig. 41). Shorter than mesosoma; ovipositor sheath not exserted.

\section{Notes}

Of the original type material, five females and two leaf-remnants with attached egg shells were found, all with labels by Sheng. One female labeled with "species name: Anastatus papillosae sp. nov. designated by Sheng Jinkun", here considered to be the holotype, has another two labels: "Shicheng, Jiangxi Prov., host: Tessaratoma papillosa" and "1979, Collector:". Another four females have the same collection label as the holotype. The holotype lacks both flagella. Of the paratypes, two are intact; one has lost both flagella, the middle legs, the left hind leg and right metatibia; one has only the head, left antenna, a broken right fore wing, as well as one middle and one hind leg remaining.

The published data for this species gives the date of collection as 1989, but the labels on the specimens have the printed year as " 198 _", and a written date "79", with "7" covering the number " 8 ". Consequently, we suspect these specimens were collected in 1979, but that Sheng made a mistake with the published date.

\section{Remarks}

The most important differential characters of females are as follow: 1) profemur ventrally bearing a blunt tooth at apical quarter (Fig. 47); 2) anterior convex part of medial lobe U-shaped (Fig. 45); 3) posterior concave part of medial lobe with setae in two radial patterns (Fig. 45); 4) anellus wider than long, and $8^{\text {th }}$ flagellomere longer than wide; 5) SMV $1.3 \times$ as long as MV. Females most closely resemble those of A. dexingensis, but $A$. dexingensis has a sharp profemural tooth $(c f$. Figs 7,47$)$ and the anterior convex part of medial lobe is V-shaped ( $c f$. Figs 4, 45). Using Kalina (1981), A. shichengensis keys out to $A$. splendens, but differs from the latter species in the same features given under remarks for $A$. dexingensis. 

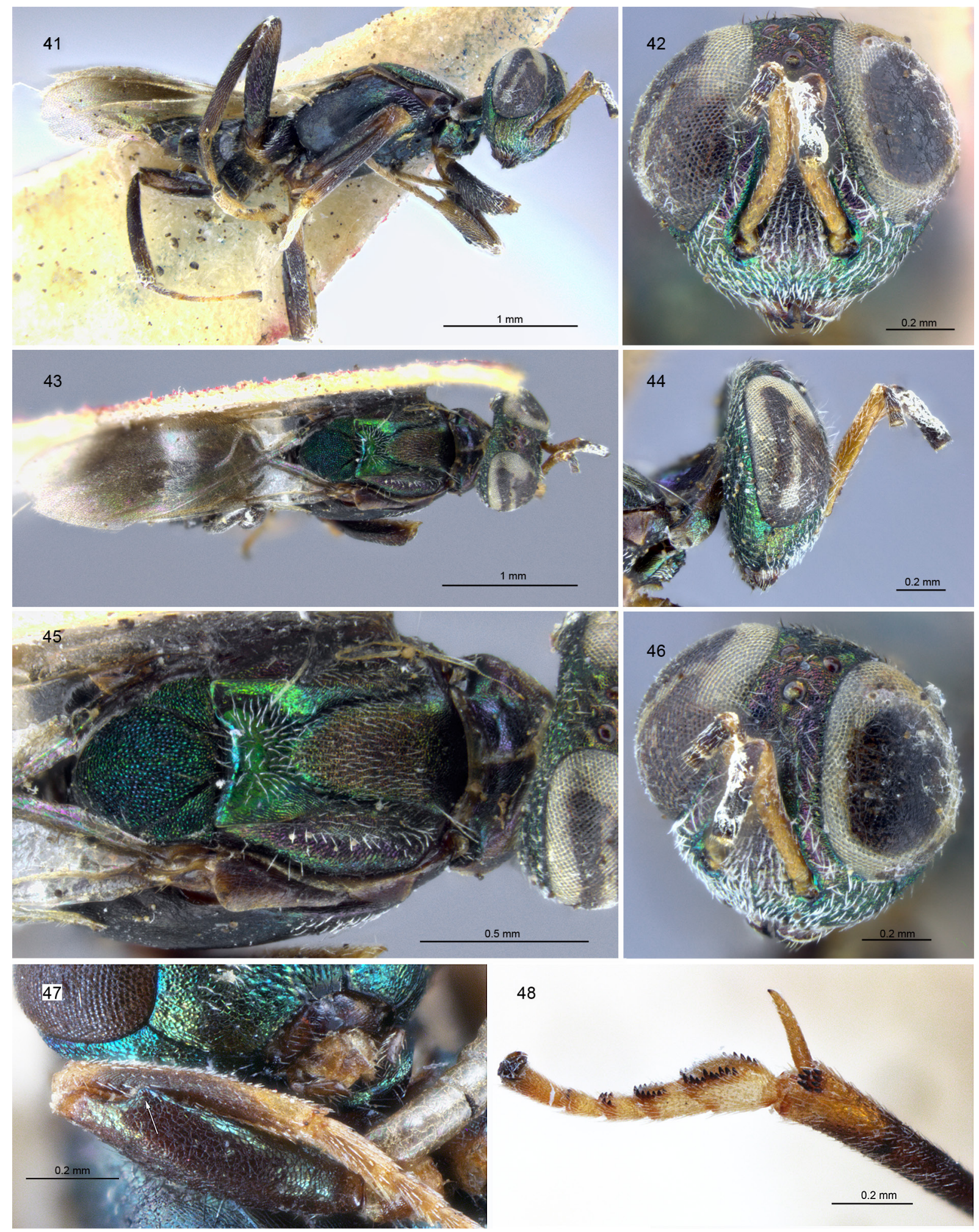

Figs 41-48. Anastatus shichengensis, ㅇ. 41-46. Holotype. 41. Body, lateral view. 42. Head, frontal view. 43. Body, dorsal view. 44. Head, lateral view. 45. Mesosoma, dorsal view. 46. Head, frontolateral view. -47-48. Paratype. 47. Front leg (the tooth is arrowed). 48. Apex of mesotibia and mesotarsus. 


\section{Discussion}

In landmass, China is only slightly smaller than Europe. Fourteen species of Anastatus are recorded from China (Noyes 2016; Yang et al. 2015) and 16 from Europe (Noyes 2016). Though these numbers are also similar, Europe consists of just one biogeographic realm - the Palaearctic - whereas China encompasses both the Palearctic and Oriental regions. Moreover, the comparative lack of taxonomic research on Chinese eupelmids in the past means that almost nothing is known of the fauna of China compared to Europe. It is to be expected that with more comprehensive surveys and future revisions of Anastatus from China, the known number of species will increase greatly, eventually exceeding the number in Europe. Present reexamination of type material of the six species of Anastatus described by J.K. Sheng and coauthors from the Oriental region of China demonstrates that all six species appear to be valid.

Most of the specimens from Sheng's collection are poorly preserved, damaged by mildew or eaten by insects. This was a result not only of the humid climate of Nanchang, but also of the financial condition of most Chinese collections in the 1980s and 1990s. Nanchang is the capital of Jiangxi Province in southeastern China, with a humid subtropical climate and four distinct seasons. The East Asian rainy season in particular, which lasts for nearly two months during the later spring and early summer, incurs a high level of ambient humidity and encourages development of mold on specimens. Furthermore, China had very limited funds for basic science and research in the 1980s to 1990. As a result, many insect collections lacked air conditioners, dehumidifiers, and other resources for adequate preservation, meaning that specimens were vulnerable to damage by moisture or insects. Nowadays, storage conditions for specimens in most Chinese universities and museums are much better. However, heritage specimens still need cleaning, repairing, photographing and redescribing, which will be a necessary part of comprehensive revisionary systematics in China in the future.

\section{Acknowledgements}

We thank Prof. Hongyi Wei and Dr. Weichun Li (Jiangxi Agricultural University, Nanchang, China) for their generous help when the first author examined Sheng's collection. Thanks also to Michael Gates (USNM, Washington D.C., USA) for allowing the author to examine type material in the collection during a visit in April 2016, and to Lisa Bearss (AAFC, Ottawa, Canada) for her help with specimen imaging. This project is supported by the National Natural Science Foundation of China (31301910, 41501058), Research Fund for the Doctoral Program of Higher Education of China (20133515120003), Natural Science Foundation of Fujian Province, China (2014J05032).

\section{References}

Ashmead W.H. 1904. Descriptions of new Hymenoptera from Japan. II. Journal of the New York Entomological Society 12 (3): 146-165.

Gibson G.A.P. 1989. Phylogeny and classification of Eupelmidae, with a revision of the world genera of Calosotinae and Metapelmatinae (Hymenoptera: Chalcodoidea). Memoirs of the Entomological Society of Canada 149: 1-121.

Gibson G.A.P. 1995. Parasitic wasps of the subfamily Eupelminae: classification and revision of world genera (Hymenoptera: Chalcidoidea, Eupelmidae). Memoirs on Entomology, International 5, Associated Publishers, Gainesville.

Gibson G.A.P. 1997. Chapter 2. Morphology and terminology. In: Gibson G.A.P., Huber J.T. \& Woolley J.B. (eds) Annotated Keys to the Genera of Nearctic Chalcidoidea (Hymenoptera): 16-44. NRC Research Press, Ottawa. 
PENG L. et al., Sheng Chinese Anastatus species redescription

Gibson G.A.P. 2009. Revision of New World Spalangiinae (Hymenoptera: Pteromalidae). Zootaxa 2259: 1-159.

Gibson G.A.P. 2011. The species of Eupelmus (Eupelmus) Dalman and Eupelmus (Episolindelia) Girault (Hymenoptera: Eupelmidae) in North America north of Mexico. Zootaxa 2951: 1-97.

Gibson G.A.P. \& Fusu L. 2016. Revision of the Palaearctic species of Eupelmus (Eupelmus) Dalman (Hymenoptera: Chalcidoidea: Eupelmidae). Zootaxa 4081 (1): 1-331. https://doi.org/10.11646/ zootaxa.4081.1.1

Harris R.A. 1979. A glossary of surface sculpturing. Occasional Papers in Entomology, Sacramento California 28: 1-31.

Huang M.D., Mai S.H., Wu W.N. \& Poo C.L. 1974. The bionomics of Anastatus sp. and its utilisation for control of Tessaratoma papillosa Drury. Acta Entomologica Sinica 17 (4): 362-382.

Ishii T. 1938. Chalcidoid- and proctotrypoid-wasps reared from Dendrolimus spectabilis Butler and D. albolineatus Matsumura and their insect parasites, with descriptions of three new species. Konty $\hat{u} 12$ (3): 97-105.

Kalina V. 1981. The Palaearctic species of the genus Anastatus Motschulsky, 1860 (Hymenoptera, Chalcidoidea, Eupelmidae) with descriptions of new species. Silvaecultura Tropica et Subtropica, Prague 8: 3-25.

Leksawasdi P. \& Kumchu C. 1991. Mass rearing and releasing of the parasitoid Anastatus sp. Kasetsart Journal - Natural Sciences 25 (1): 47-58.

Liao D.X., Li X.L, Pang X.F. \& Chen T.L. 1987. Hymenoptera: Chalcidoidea (1). Economic Insect Fauna of China, No. 34. Science Press, Beijing.

Narendran T.C. 2009. A review of the species of Anastatus Motschulsky (Hymenoptera: Chalcidoidea: Eupelmidae) of the Indian subcontinent. Journal of Threatened Taxa 1 (2): 72-96. https://doi. org/10.11609/JoTT.01903.72-96

Nikol'skaya M.N. 1952. Chalcidy fauny SSR. Opred. po faune SSSR, 44. Moskva, Leningrad.

Noyes J.S. 2016. Universal Chalcidoidea Database. Available from http://www.nhm.ac.uk/our-science/ data/chalcidoids/ [accessed 14 Feb. 2016]

Peng L.F. \& Lin N.Q. 2012. Recent advances in Eupelmidae (Hymenoptera: Chalcidoidea) systematics. Fujian Journal of Agricultural Sciences 27 (11): 1269-1273.

Sheng J.K., Wang G.H., Yu Y.X. \& Yu J.C. 1997. Four new species of Anastatus Motschulsky (Hymenoptera: Eupelmidae) from China. Entomotaxonomia 19(1): 58-64.

Sheng J.K. \& Yu Y.X. 1998. Two new species of Anastatus Motschulsky from China (Hymenoptera, Chalcidoidea, Eupelmidae). Wuyi Science Journal 14: 5-8.

Yang Z.Q., Choi W.Y., Cao L.M., Wang X.Y. \& Hou Z.R. 2015. Anew species of Anastatus (Hymenoptera: Eupelmidae) from China, parasitizing eggs of Lycorma delicatula (Homoptera: Fulgoridae). Zoological Systematics 40 (3): 290-302.

Manuscript received: 13 April 2016

Manuscript accepted: 13 July 2016

Published on: 6 March 2017

Topic editor: Gavin Broad

Desk editor: Chloe Chester 
Printed versions of all papers are also deposited in the libraries of the institutes that are members of the EJT consortium: Muséum national d'Histoire naturelle, Paris, France; Botanic Garden Meise, Belgium; Royal Museum for Central Africa, Tervuren, Belgium; Natural History Museum, London, United Kingdom; Royal Belgian Institute of Natural Sciences, Brussels, Belgium; Natural History Museum of Denmark, Copenhagen, Denmark; Naturalis Biodiversity Center, Leiden, the Netherlands. 